\title{
PERFIL DO DESENVOLVIMENTO MOTOR E COGNITIVO DE CRIANÇAS COM IDADE ENTRE ZERO E UM ANO MATRICULADAS NAS CRECHES PÚBLICAS DA REDE MUNICIPAL DE EDUCAÇÃO DE PRESIDENTE PRUDENTE
}

Edelvira de Castro Quintanilha Mastroianni ${ }^{1}$

Tânia Cristina Bofi ${ }^{2}$

Augusto Cesinando de Carvalho ${ }^{3}$

\section{Resumo}

A estimulação das crianças nos primeiros anos de vida é fundamental, pois é nessa fase que ocorre a maior maturação do Sistema Nervoso Central. Sendo a creche um ambiente onde um grande número de crianças pequenas passa grande parte do seu tempo, a qualidade de seus serviços é cada vez mais tópico para discussão. O propósito do estudo foi avaliar o desenvolvimento motor e cognitivo de crianças com idade entre zero e um ano, matriculadas nas creches públicas de Presidente Prudente. Os resultados mostraram que a idade cronológica das crianças foi de 10,08 meses, já a idade motora ficou em 9,69 meses e a cognitiva em 9,10 meses, em média. Esses resultados permitem inferir que as crianças estudadas, estão aproveitando a estimulação recebida. Entretanto, apesar da estrutura atual não estar trazendo prejuízos significativos ao desenvolvimento infantil é fundamental buscarmos a superação de limites e a melhora das condições gerais das creches.

Palavras-chave: avaliação, desenvolvimento motor, cognição, creche.

\section{Introdução}

O Sistema Nervoso apresenta uma intensa evolução dinâmica nos primeiros anos de vida, devido aos processos de mielinização e diferenciação neuronal de suas estruturas. Esse crescimento acelera-se progressivamente ao nascimento e nos primeiros 24-36 meses de vida, sendo denominado de "período crítico" do desenvolvimento (PASCUAL, 1995). A crescente maturação do córtex cerebral promove a melhora das funções motoras, com aquisição do controle motor e das habilidades motoras. Por outro lado, a prática motora também influencia o desenvolvimento da mielinização e da organização estrutural do Sistema Nervoso Central, sendo a experiência e a repetição muito importantes nos mecanismos de maturação cerebral durante a vida extra-uterina (BARROS, FRAGOSO, OLIVEIRA et. al, 2003).

Portanto, o desenvolvimento do ser humano está subordinado a dois grupos de fatores: os fatores da hereditariedade e adaptação biológica (maturação de certos tecidos nervosos, aumento do tamanho e complexidade do Sistema Nervoso Central, crescimento de ossos e músculos) e os fatores ambientais (experiência e estimulação sensório-motriz, nutrição, condições sócio-econômicas e afetivas) (PIAGET, 1973).

Desta forma, a estimulação da criança desde sua mais tenra idade é fundamental. Deve haver nesse período o máximo de satisfação de suas necessidades básicas. Pois, as crianças que possuem carência de estímulos corporais e ambientais nessa fase poderão apresentar dificuldades no decorrer de outros estágios do

\footnotetext{
${ }^{1}$ Mestre em Educação, Docente do Departamento de Educação Física da FCT/ UNESP; ${ }^{2}$ Mestre em Educação, Docente do Departamento de Fisioterapia da FCT/ UNESP; ${ }^{3}$ Doutor em Ciências, Docente do Departamento de Fisioterapia da FCT/ UNESP edelviram@terra.com.br
} 
desenvolvimento, com risco de chegar ao período escolar com déficits acumulados em relação às habilidades mínimas necessárias para que possam adquirir novos comportamentos que delas serão exigidos (LAMPRÉIA, 1985).

Para Lampréia (1985), o atraso no desenvolvimento psicomotor das crianças em desvantagem, deve ser atribuído, em grande parte, ao fato de terem crescido num ambiente carente de estímulos facilitadores dos mesmos.

As creches, no momento de sua concepção, possuíam caráter puramente assistencialista, constituindo-se basicamente em um lugar onde a criança recebia abrigo, alimentação e algum atendimento em higiene e saúde enquanto seus pais trabalhavam. De modo que essas instituições representavam um grande risco ao bom desenvolvimento infantil (MERISSE, 1997).

A partir da inclusão da creche no sistema educativo, através da Constituição de 1988 (BRASIL, 1988), a concepção de uma instituição voltada para uma ação educativa promotora do desenvolvimento infantil começa a ser valorizada. Desde então, aspectos como estimulação, interação, jogos, imitação, recreação, etc, passam a ser destacados como elementos fundamentais para o trabalho realizado em qualquer creche e para as famílias e crianças que se utilizam desse serviço (BOFI, 2000).

Baseando-se nesses aspectos, este trabalho tem como propósito avaliar o desenvolvimento motor e cognitivo de crianças de zero a um ano matriculadas nas creches públicas de Presidente Prudente e, a partir dos resultados, caracterizar o perfil psicomotor dessas crianças, tendo em vista colaborar com uma visão da influência do ambiente de creche nos desfechos infantis.

\section{Metodologia}

Fizeram parte da pesquisa 35 crianças de ambos os sexos com idade entre 5 meses e 1 ano matriculadas no berçário I de 5 creches públicas de Presidente Prudente. As instituições foram selecionadas através de um sorteio aleatório.

A proposta inicial foi avaliar o desenvolvimento motor e cognitivo de crianças de 0 a 1 ano, entretanto, por não encontrar nenhuma criança abaixo de 5 meses passou-se a expressar os resultados a partir do quinto mês de vida.

Para avaliação da amostra utilizou-se o "Inventário Portage Operacionalizado" - IPO (WILLIANS; AIELLO, 2001). Este é composto por um inventário comportamental ("Portage Checklist") que lista 580 comportamentos distribuídos em cinco áreas (socialização, linguagem, auto-cuidados, cognição e desenvolvimento motor) por faixa etária de zero a seis anos e uma sexta área específica para bebês de zero a quatro meses ou para crianças com tal nível de funcionamento, que se denomina estimulação infantil (BLUMA et al., 1978).

$\mathrm{Na}$ presente pesquisa foi considerada somente as áreas da cognição, desenvolvimento motor e estimulação infantil para a faixa etária estudada. A área da cognição compõe-se de 14 itens que avaliam a linguagem receptiva, noção espacial e o estabelecimento de relações entre semelhanças e diferenças; a área do desenvolvimento motor é constituída por 45 comportamentos que avaliam os movimentos coordenados por pequenos e grandes músculos e a área de estimulação infantil, também composta por 45 itens, nada mais é que um detalhamento dos primeiros itens de todas as outras cinco áreas, sendo avaliada no bebê que apresentar erros em 50\% dos comportamentos listados na primeira metade de itens da faixa etária de zero a um ano nas áreas do desenvolvimento motor e/ou cognição.

Para a padronização do registro do desempenho da criança em cada prova fez-se uso de uma Folha de Registro, obtendo-se o número de acertos em cada prova e a respectiva porcentagem de sucesso. A partir do total de itens testados e do total de acertos foi calculada a idade motora e cognitiva da criança através de uma regra de três. Além disso, através da subtração das idades cognitiva e motora alcançadas nos testes pela idade cronológica obtida da data de nascimento, determinou-se o atraso cognitivo e motor da criança.

Para análise dos dados foi usado o software estatístico SAS - Statistical Analysis System - Versão 6.12, considerando o nível crítico de confiança de $95 \%(0,05)$ em todos os cálculos. 


\section{Resultados}

Com relação ao comportamento das idades da amostra total obteve-se idade cronológica média (ICR) de aproximadamente 10,08 meses, idade motora média (IMO) de 9,69 meses, idade cognitiva média de 9,01 meses e idade da estimulação infantil média (IEI) de 3,48 meses. Portanto, verifica-se diferença significativa da ICR apenas em relação à IEI, visto que em uma análise do desenvolvimento infantil é ampla a faixa etária considerada de normalidade, podendo variar de \pm 6 meses dependendo da aquisição em questão. A Tabela 1 exibe a estatística descritiva do comportamento dessas idades.

Tabela 1. Estatística descritiva das idades da amostra total.

\begin{tabular}{cccccc}
\hline & N & Média & Desvio Padrão & Mínimo & Máximo \\
\hline ICR & 35 & 10,08 & 2,12 & 5,00 & 12,97 \\
IMO & 30 & 9,69 & 2,10 & 4,80 & 12,37 \\
ICO & 30 & 9,01 & 1,63 & 6,00 & 11,14 \\
IEI & 5 & 3,48 & 0,34 & 3,11 & 3,91 \\
\hline
\end{tabular}

Das 35 crianças avaliadas, 4 apresentaram patologia diagnosticada e 31 não possuíam patologia. As tabelas 2 e 3 analisam separadamente o perfil desses dois grupos. Observou-se que as crianças com patologia possuíam idade cronológica média (ICR) maior (12,25 meses) que as crianças sem patologia $(9,80$ meses). Entretanto, os valores obtidos da idade cognitiva média (ICO) e da idade da estimulação infantil (IEI) das crianças patológicas apresentaram-se inferiores quando comparados ao das não patológicas, fato que indica uma grande diferença entre a ICR e os resultados obtidos nos testes. Essa diferença é chamada de atraso cognitivo (ACO) e atraso da estimulação infantil (AEI), respectivamente. Apesar da idade motora média (IMO) das crianças patológicas ser numericamente maior que a encontrada nas crianças sem patologia, aquelas apresentaram atraso motor (AMO) maior do que estas, pois a diferença em relação à ICR é maior. Nas crianças sem patologia houve diferença significativa apenas entre a ICR e a IEI.

Tabela 2. Estatística descritiva das idades das crianças sem patologia.

\begin{tabular}{cccccc}
\hline & N & Média & Desvio Padrão & Mínimo & Máximo \\
\hline ICR & 31 & 9,80 & 2,05 & 5,00 & 12,97 \\
IMO & 29 & 9,66 & 2,13 & 6,00 & 11,14 \\
ICO & 29 & 9,05 & 1,64 & 4,80 & 12,37 \\
IEI & 2 & 3,60 & 0,19 & 3,46 & 3,73 \\
\hline
\end{tabular}


Tabela 3. Estatística descritiva das idades das crianças com patologia.

\begin{tabular}{cccccc}
\hline & N & Média & Desvio Padrão & Mínimo & Máximo \\
\hline ICR & 4 & 12,25 & 1,45 & 10,07 & 12,97 \\
IMO & 1 & 10,40 & - & 10,40 & 10,40 \\
ICO & 1 & 7,71 & - & 7,71 & 7,71 \\
IEI & 3 & 3,41 & 0,44 & 3,11 & 3,91 \\
\hline
\end{tabular}

Para verificar se existe diferença entre as creches foi aplicado um teste de Kruskall-Wallis (teste nãoparamétrico) dentre o total de crianças de cada creche. A Tabela 4 mostra que não há diferença significativa entre as unidades (p_valor= 0,0537) para a idade cronológica. Essa paridade permitiu a comparação das idades da estimulação infantil, motora e cognitiva entre as instituições, como expõe as Tabelas 5, 6 e 7 respectivamente. Os resultados permitem concluir que para essas três variáveis também não houve diferença significativa entre as creches, sendo o p_valor IEI $=0,1653$, o p_valor $\mathrm{IMO}=0,0857$ e o p_valor $\mathrm{ICO}=0,3595$. Observou-se que apesar das creches 1 e 4 possuírem crianças patológicas, isso não acarretou desvantagens significativas para essas creches quando comparadas com a creche 3 , que não possuía crianças patológicas mas que teve a estimulação infantil avaliada em duas de suas crianças.

Tabela 4. Comparação da idade cronológica entre as creches.

\begin{tabular}{cccccc}
\hline Creche & N & Média & Desvio Padrão & Mínimo & Máximo \\
\hline $\mathbf{1}$ & 12 & 11,30 & 2,12 & 6,43 & 12,97 \\
$\mathbf{2}$ & 8 & 9,67 & 1,41 & 8,03 & 11,53 \\
$\mathbf{3}$ & 7 & 8,69 & 2,49 & 5,00 & 12,00 \\
$\mathbf{4}$ & 5 & 9,13 & 1,22 & 7,10 & 10,10 \\
$\mathbf{5}$ & 3 & 11,11 & 1,71 & 9,13 & 12,10 \\
\hline
\end{tabular}

Tabela 5. Comparação da idade da estimulação infantil entre as creches.

\begin{tabular}{cccccc}
\hline Creche & N & Média & Desvio Padrão & Mínimo & Máximo \\
\hline $\mathbf{1}$ & 2 & 3,16 & 0,064 & 3,11 & 3,20 \\
$\mathbf{3}$ & 2 & 3,60 & 0,19 & 3,46 & 3,73 \\
$\mathbf{4}$ & 1 & 3,91 & - & 3,91 & 3,91 \\
\hline
\end{tabular}


Tabela 6. Comparação da idade motora entre as creches.

\begin{tabular}{cccccc}
\hline Creche & N & Média & Desvio Padrão & Mínimo & Máximo \\
\hline $\mathbf{1}$ & 10 & 10,03 & 2,29 & 5,86 & 12,37 \\
$\mathbf{2}$ & 8 & 9,13 & 2,06 & 6,13 & 11,20 \\
$\mathbf{3}$ & 5 & 10,59 & 0,63 & 9,86 & 11,46 \\
$\mathbf{4}$ & 4 & 7,67 & 2,45 & 4,80 & 10,40 \\
$\mathbf{5}$ & 3 & 11,20 & 0,27 & 10,93 & 11,46 \\
\hline
\end{tabular}

Tabela 7. Comparação da idade cognitiva entre as creches.

\begin{tabular}{cccccc}
\hline Creche & N & Média & Desvio Padrão & Mínimo & Máximo \\
\hline $\mathbf{1}$ & 10 & 9,34 & 1,91 & 6,00 & 11,14 \\
$\mathbf{2}$ & 8 & 9,10 & 1,44 & 6,85 & 11,14 \\
$\mathbf{3}$ & 5 & 8,36 & 1,62 & 6,00 & 10,28 \\
$\mathbf{4}$ & 4 & 8,07 & 1,67 & 6,00 & 10,00 \\
$\mathbf{5}$ & 3 & 9,99 & 0,50 & 9,42 & 10,28 \\
\hline
\end{tabular}

\section{Discussão}

Através da análise dos resultados obtidos, constatou-se que apenas 5 crianças $(14,29 \%$ do total) classificaram-se na área da estimulação infantil, específica para bebês de 0 a 4 meses ou para crianças com tal nível de funcionamento. Dessas, 3 apresentaram patologia, fato que explica o atraso no desenvolvimento motor e cognitivo em relação à idade cronológica. A inclusão na área da estimulação infantil das outras 2 crianças sem patologia, justifica-se pela baixa idade cronológica desses bebês, sendo 6,13 e 5 meses, com idades obtidas na avaliação de 3,73 e 3,46 meses respectivamente. Portanto, os atrasos encontrados nesses casos são de 2,40 e 1,54 meses, não representando valores significativos em termos de desenvolvimento infantil, pois como salientaram vários autores como Piper e Darrah (1994); Moraes (1998); Burns e McDonald (1999) e Barros, Fragoso, Oliveira et. al. (2003) a faixa etária de normalidade para aquisição dos marcos do desenvolvimento é ampla, assim por exemplo, o andar pode variar de 9 a 15 meses, dependendo do potencial genético e da influência dos fatores ambientais. Da mesma forma, as restantes 29 crianças sem patologia (82,86\% do total) apresentaram idades atingidas nos testes muito semelhantes à idade cronológica, com ligeira diferença de 0,75 meses abaixo para idade motora e 0,14 meses para idade cognitiva, em média. Tais resultados confirmam a definição de Gesell (2000), quando este diz que os testes comportamentais estabelecem a normalidade e revelam até mesmo desvios insignificantes em crianças relativamente sadias.

Portanto, a avaliação do desenvolvimento tem um lugar importante na proteção e assistência preventiva de crianças normais, com a vantagem de ser o procedimento de avaliação utilizado um instrumento de baixo custo, simples aplicação e eficiente, podendo ser prontamente incorporado no controle do bem-estar dos bebês e nos exames periódicos de saúde.

Entretanto, infelizmente a prevenção e a detecção precoce de alterações do desenvolvimento infantil são práticas pouco aplicadas no Brasil segundo Lima, Barbarini, Gagliardo et. al. (2004). Essa preocupação justifica-se pois a simples observação rotineira do comportamento permite a identificação precoce de quaisquer anormalidades e 
possibilita a antecipação do processo de intervenção logo no início da vida da criança, garantindo a estimulação necessária em todos os aspectos fundamentais para seu desenvolvimento global e evitando intervenções terapêuticas mais caras e prolongadas no futuro.

O fato de apenas as crianças patológicas ter apresentado déficits significativos em seu desenvolvimento permite inferir que as crianças estudadas estão aproveitando a estimulação recebida, tanto no nível das vivências motoras, quanto da formação de conceitos e da socialização de forma geral.

Esses resultados, quando comparados com os estudos realizados por Bofi (2000), que observou defasagem no desenvolvimento sensório-motor de crianças de 0 a 2 anos das creches de Presidente Prudente, possivelmente indicam uma melhora na qualidade do serviço prestado há 5 anos.

Embora um olhar mais global ateste a favor do desenvolvimento cognitivo e motor das crianças, é fundamental buscarmos a superação de limites e a melhora das condições gerais das creches. Pois, apesar da estrutura atual não estar trazendo prejuízos significativos ao desenvolvimento infantil, ainda há muito que ser feito para que os ideais de cuidado e educação sejam alcançados.

Prova disso foi constatada na observação do cotidiano das creches, o qual evidenciou fases bem pouco vivenciadas do desenvolvimento motor normal, corroborando com os achados de Vigiano et al. (1998) em sua experiência com creches.

Há que se refletir sobre a importância desses achados, pois conforme ressalta Gesell (1956), nenhum estágio ou aquisição é dispensável, já que o desenvolvimento ocorre numa seqüência de transformações. Assim, cada etapa adquirida em determinado momento é consequiência de todas as anteriormente obtidas e será a preparação e a base para as etapas subseqüentes, diz Brandão (1992).

Nesse sentido, apoiamos Seabra e Moura (2005) ao afirmar que tanto em casa como na creche, diversas situações do dia-a-dia do bebê são construtivas para o desenvolvimento, inclusive o momento de alimentação e higiene. Gradativamente a criança vai deixando a passividade e tornando-se mais ativa nestes processos. Como valoriza Abramovicz (1991) é por meio da rotina que a criança pequena realiza suas trocas com as pessoas e com a realidade exterior. Por isso, muitas atividades têm importância para ela, tais como: comer, dormir, tomar banho, trocar as fraldas, vestir, despir, mexer, engatinhar, correr, cair, levantar, trocar, pegar, chorar, gritar, chupar. Para vários autores, dentre eles Abramovicz (1991); Barbosa (1998); Bofi (2000) é assim que a criança vai realizando seu aprendizado, construindo seu eu, desenvolvendo seu corpo e apropriando-se da sua cultura.

Um ponto positivo da rotina das creches é que, segundo Bofi (2000), a existência de uma rotina faz-se necessária para que a criança adquira gradativamente a noção de tempo, fundamental para que ela aprenda a organizar-se em função dele. Inoue (1998) relata que a percepção desta relação tempo-duração do trabalho oferece à criança condições de autodisciplina, à medida que ela começa a perceber a sequiência rotineira das atividades diárias, indispensáveis a um desenvolvimento adequado.

Portanto, como salientou Barbosa (1998), os conceitos de cuidar e educar devem ser vistos como um sistema integrado que amplia o cuidado doméstico e promove o desenvolvimento global da criança. Assim, as atividades de rotina diária fazem parte do processo educacional, entretanto não são exclusivos.

A capacitação dos profissionais é, portanto, essencial, devendo-se fundamentar as ações na concepção de criança como cidadão, como pessoa em desenvolvimento, como sujeito ativo da construção de seu conhecimento. É por isso que a profissional que atua na creche deve ter clareza das concepções de criança e, principalmente, da educação infantil e dos processos de desenvolvimento e aprendizagem para estimular o crescimento da mesma.

A comparação entre as creches mostrou que não houve diferença estatisticamente significativa na avaliação da idade cronológica, da estimulação infantil, motora e cognitiva, o que indica que as creches possuem um perfil semelhante, apesar de se localizarem em bairros distintos da cidade. Um fato que poderia explicar essa homogeneidade é devido aos bairros serem todos considerados periféricos, atendendo uma população com condição sócio-econômica baixa e semelhante.

Assim, este, como outros estudos atuais, aponta para uma posição de defesa da instituição creche, desde que sejam respeitadas as condições de atendimento à criança, ou seja, desde que a creche se torne um espaço favorecedor da aprendizagem. Além de estar fundamentada no conceito de formação integral da criança, implicando em uma evolução favorável de ordem física, motora, cognitiva, afetiva, psíquica, social e moral. 
Portanto, concordamos plenamente com o conceito de creche de Veríssimo e Fonseca (2003) como um direito da criança, como um espaço de vida e saúde, de interações, de descobertas e aprendizagem, de desenvolvimento das potencialidades e da cidadania infantil.

\section{Conclusão}

Ao final da pesquisa, constatou-se que a creche, ao oferecer seus serviços, não atende só às necessidades dos pais em termos de aumentar a disponibilidade do seu tempo para o trabalho, mas permitem à criança um desenvolvimento saudável e, de maneira geral, compatível com o que se espera de bebês de zero a um ano.

Entretanto, o benefício à criança está intimamente ligado à qualidade dos cuidados e da educação, à interação e à sensibilidade aos sinais da criança, fatores que devem ser considerados fundamentais para o trabalho realizado em qualquer creche e para as famílias e crianças que se utilizam desse serviço.

Nesse aspecto, ainda há muito que ser adequado para que um ideal de atendimento seja atingido. Contudo, essa não parece ser tarefa difícil, tampouco impossível, pois basta a possibilidade de a criança estar em contato com outras pessoas, adultos e crianças, que estimulem suas potencialidades, de ser atendida com carinho e atenção e de receber subsídios que propiciem seu desenvolvimento, que um bom desenvolvimento motor e cognitivo será alcançado.

Portanto, embora a creche tenha sido criada fundamentalmente para atender às necessidades políticas e econômicas da sociedade, ela pode ser um ambiente educativo valorizado, onde o acesso aos bens culturais seja facilitado e oferecido à criança, estimulando o seu desenvolvimento, respeitando a sua dignidade, sua alteridade e seus direitos de cidadã. Tal como garante a Constituição de 1988, que define a creche como "direito da criança, opção da família e dever do Estado”.

Além disso, o trabalho também amplia a atuação do fisioterapeuta para além das áreas tradicionais já ocupadas, ao constatar a relevância da sua participação na área educacional. Tendo como papel avaliar o desenvolvimento infantil e elaborar, junto às orientadoras pedagógicas, práticas que possibilitem o desenvolvimento global das crianças. Com isso, o fisioterapeuta contribui tanto para a formação dos profissionais de educação infantil quanto para melhoria da qualidade dos serviços prestados pelas escolas (creches).

\section{Referências Bibliográficas}

ABRAMOVICZ, A. y WAJSKOP, G. (1991). Creches: atividades para crianças de zero a seis anos. São Paulo: Moderna,.

BARBOSA, A. A. (1998). Educar e cuidar: a formação do educador de creche frente às novas exigências. Comunicações, 5, (2), p.133-139.

BARros, K. M. F. T. de; FRAGOSO, A. G. C.; OLIVEIRA, A. L. B. de et. al. (2003). Influências do ambiente podem alterar a aquisição de habilidades motoras? Uma comparação entre pré-escolares de creches públicas e escolas privadas. Arq. Neuro-Psiquiatria, (61), (2 $\left.2^{\mathrm{a}}\right)$, p. 170-175.

BOFI, T. C. (2000). O atendimento infantil nas creches de Presidente Prudente - área do desenvolvimento sensório-motor. Universidade do Oeste Paulista,. Dissertação de mestrado.

BRASIL. (1988). Constituição da República Federativa do Brasil. Brasília. 
BRANDÃO, J. S. (1992). Bases do tratamento por estimulação precoce da paralisia cerebral. São Paulo: Memnon.

GESEll, A. y AMATRUdA, C. S. (2000). Psicologia do Desenvolvimento do Lactente e da Criança Pequena: Bases Neuropsicológicas e Comportamentais. São Paulo: Atheneu,.

GESELL, A. (1956). The mental growth of prematurely born infants. J. Pediatria, 2, (6), p. 67-80.

BURNS, Y. R. y McDONALD, J. (1999). Fisioterapia e Crescimento na Infância. São Paulo: Ed. Santos.

LAMPRÉIA, C. (1985). A prevenção no atraso do desenvolvimento: a prevenção na psicologia. Ciência e Profissão, $5,(1)$ p. 25-30.

LIMA, M. C. M. P. y BARBARINI, G. C. y GAGLIARDO, H. G. R. et al. (2004). Observação do desenvolvimento de linguagem e funções auditiva e visual em lactentes. Revista de Saúde Pública, 38, (1), p.106-112.

MERISSE, A. (1997). Origem das instituições de atendimento à criança: o caso das creches. En MERISSE, A.y JUSTO, J. S. y ROCHA, L. C. Da y VASCONCELOS, M. S. Lugares da infância: reflexões sobre a história da criança na fábrica, creche e orfanato. (p. 25-51), São Paulo: Arte Ciência.

MORAES, J.C. et al. (1998). O engatinhar: um estudo da idade de seu aparecimento e de sua relação com a aquisição da marcha. Revista de Fisioterapia da Universidade de São Paulo, 5, (2), p. 11-19.

INOUE, A. A. et al. (1998). Referencial Curricular Nacional para a Educação Infantil: desenvolvimento pessoal e social, brincar, movimento, conhecimento de si e do outro. Brasília: Ministério da Educação, Secretaria da Educação Fundamental.

PASCUAL, R. (1995). Efectos de la estimulación vs. Privación sensório-motriz sobre el desarrollo neuronal en la corteza motora. Rev. Chi. Neuro-Psiquiat., 33, p. 297-304.

PIAGET, J. (1973). A formação do símbolo na criança. Rio de Janeiro: Zahar,.

PIPER, M. C. y DARRAH, J. (1994). Motor assesment of the developing infant. Philadelphia: W.B. Sounders Company.

SEABRA, K. C. y MOURA, M. L. S. (2005). Alimentação no ambiente de creche como contexto de interação nos primeiros dois anos de um bebê. Psicologia em estudo, 10, (1), p. 77-86.

VERISSIMO, M. de La Ó R. y FONSECA, R. M. G. S. da. (2003). O cuidado da criança segundo trabalhadoras de creches. Revista Latino-Americana de Enfermagem,11, (1), p.28-35. 
VIGIANO, A. P. et al. (1998). A importância de estimular as fases do desenvolvimento motor normal de 0 a 18 meses. Fisioterapia em Movimento, 10, p. 31-43. 